\title{
TU/e emonownen

\section{Electrical conductive behavior of polymer composites prepared with aqueous graphene dispersions}

\section{Citation for published version (APA):}

Gomes Ghislandi, M., Tkalya, E., Alekseev, A., Koning, C. E., \& de With, G. (2015). Electrical conductive behavior of polymer composites prepared with aqueous graphene dispersions. Applied Materials Today, 1(2), 88-94. https://doi.org/10.1016/j.apmt.2015.11.001

\section{Document license:}

TAVERNE

DOI:

10.1016/j.apmt.2015.11.001

Document status and date:

Published: 15/12/2015

\section{Document Version:}

Publisher's PDF, also known as Version of Record (includes final page, issue and volume numbers)

\section{Please check the document version of this publication:}

- A submitted manuscript is the version of the article upon submission and before peer-review. There can be important differences between the submitted version and the official published version of record. People interested in the research are advised to contact the author for the final version of the publication, or visit the $\mathrm{DOI}$ to the publisher's website.

- The final author version and the galley proof are versions of the publication after peer review.

- The final published version features the final layout of the paper including the volume, issue and page numbers.

Link to publication

\section{General rights}

Copyright and moral rights for the publications made accessible in the public portal are retained by the authors and/or other copyright owners and it is a condition of accessing publications that users recognise and abide by the legal requirements associated with these rights.

- Users may download and print one copy of any publication from the public portal for the purpose of private study or research.

- You may not further distribute the material or use it for any profit-making activity or commercial gain

- You may freely distribute the URL identifying the publication in the public portal.

If the publication is distributed under the terms of Article $25 \mathrm{fa}$ of the Dutch Copyright Act, indicated by the "Taverne" license above, please follow below link for the End User Agreement:

www.tue.nl/taverne

Take down policy

If you believe that this document breaches copyright please contact us at:

openaccess@tue.nl

providing details and we will investigate your claim. 


\title{
Electrical conductive behavior of polymer composites prepared with aqueous graphene dispersions
}

\author{
Marcos Ghislandi ${ }^{\mathrm{a}, \mathrm{b}, *}$, Evgeniy Tkalya ${ }^{\mathrm{d}}$, Alexander Alekseev ${ }^{\mathrm{c}}$, Cor Koning ${ }^{\mathrm{d}}$, Gijsbertus de With ${ }^{\mathrm{c}}$ \\ a Unidade Acadêmica do Cabo de Santo Agostinho (UACSA), Universidade Federal Rural de Pernambuco, BR 101 Sul, Km 97-S/N, Cabo de Santo Agostinho, PE, Brazil \\ ${ }^{\mathrm{b}}$ Center for Strategic Technologies of the Northeast (CETENE), Av. Prof. Luiz Freire 1, 50740-540 Recife, PE, Brazil \\ ${ }^{c}$ Laboratory of Materials and Interface Chemistry, Technische Universiteit Eindhoven, 5600 MB Eindhoven, The Netherlands \\ ${ }^{\mathrm{d}}$ Laboratory of Polymer Chemistry, Technische Universiteit Eindhoven, 5600 MB Eindhoven, The Netherlands
}

\section{A R T I C L E I N F O}

\section{Article history:}

Received 14 September 2015

Received in revised form 30 October 2015

Accepted 9 November 2015

\section{Keywords:}

Graphene

Latex technology

Electrical conductivity

Polymer composites

\begin{abstract}
A B S T R A C T
Graphene was produced from graphite powder using the three best known water-based conversion approaches. The first two are based on chemical oxidation methods, only differing in the reduction process, either by the use of hydrazine or by thermal expansion, respectively. The third one is based on long-term ultrasonic exfoliation. Water/surfactant solutions were prepared with these three nanofillers and latex technology concept was applied for the preparation of conductive graphene/polystyrene composites with well-dispersed graphene platelets. The samples were characterized with respect to filler properties and morphology, and their influences on electrical conductive properties of the composites were compared. Microscopic studies showed that both reduction processes lead to agglomeration/wrinkling of the platelets, even though they yield composites with high conductivity and low percolation threshold. Although mechanical ultrasound exfoliation of graphite produces less defective multi-layer graphene, these platelets have a smaller lateral size and their composites exhibit a higher percolation threshold. Differences in electronic transport behavior were observed, which suggest direct contact transport competing with tunneling.
\end{abstract}

(c) 2015 Elsevier Ltd. All rights reserved.

\section{Introduction}

The new rising star of nanofillers, graphene, with its combination of extraordinary physical and electrical properties plus the ability to be dispersed in various polymer matrices, has enabled the manufacturing of a new class of polymer composites [1,2]. Various methods to obtain graphene have been reported, since it was first mechanically isolated from graphite by Novoselov et al. [3], facilitating its production on large scales. The growing of graphene sheets from substrates [4,5] and, in particular, the controlled deposition from carbon vapor [6,7] have been recently described in literature as techniques that enable the production of single graphene layers in large 2D dimensions [8]. These materials find potential applications mainly in nanoelectronic devices $[9,10]$.

The chemical synthesis of graphene using graphite, graphite oxide (GO) or other graphite derivatives as starting materials have also been studied. The conversion of graphite into GO via Hummers [11] or similar methods is an initial stage for graphene preparation.

\footnotetext{
* Corresponding author at: Center for Strategic Technologies of the Northeast (CETENE), Av. Prof. Luiz Freire 1, 50740-540 Recife, PE, Brazil.

E-mail address: ghislandi@gmail.com (M. Ghislandi).
}

The water soluble GO can be reduced with the use of chemicals $[12,13]$ (ORchem) or by quick thermal expansion [14] (ORtherm) to form graphene. Recently, the long-term (e.g. more than $200 \mathrm{~h}$ ) simple mechanical exfoliation (sonication) of graphite dispersed in polar solvents, as well as in water/surfactant systems, were reported as methods that yield single and multilayer graphene platelets at relatively high concentrations [15-17]. The chosen conversion techniques [18] cannot only be up-scaled but also provide graphene with improved processability and, potentially, new functionality. The preparation of highly conductive paper-like graphene has been reported, yielding conductivities ranging from $10^{3}$ to $10^{4} \mathrm{~S} / \mathrm{m}$ for the above chemical exfoliation approaches $[17,19,20]$. The exfoliated dispersions are most suitable for the preparation of polymer composites with enhanced mechanical and electrical properties $[1,21-25]$.

In this work, we produce graphene dispersed in water starting from graphite following the two main chemical conversion approaches (ORchem and ORtherm) and one physical conversion, using long-term ultrasonic exfoliation (Sonic). Subsequently, graphene/polystyrene (PS) composites are prepared by the well-known latex technology. The latex concept enables the homogeneous incorporation of nanofillers into any kind of highly viscous polymer matrix, e.g. PS synthesized by emulsion polymerization 
or similar processes. There are proven significant reduction in the conductivity percolation threshold and an overall increase in the final conductivity of polymer composites when using this approach as compared to others [22,26-28]. In the following, a detailed comparison of the three chosen techniques with respect to filler morphology and conductive properties of the respective composites is presented.

\section{Experimental}

\subsection{Chemicals and polymer latex}

Sodium dodecyl sulfate (SDS) (90\%, Merck), sodium carbonate (99\%, Aldrich), sodium peroxodisulfate (SPS) (90\%, Merck), poly(sodium 4-styrene sulfonate) (PSS) (Aldrich, $M_{\mathrm{w}} 70 \mathrm{~kg} / \mathrm{mol}$ ) and sodium cholate (SC) (99\%, Aldrich) were used as received. Styrene (99\%, Merck) was passed over an inhibitor remover column prior to use. SP-2 graphite (Bay Carbon) powder was used as obtained.

PS latex was synthesized via conventional free radical emulsion polymerization. The reactor was charged with: styrene $(252 \mathrm{~g})$, SDS ( $26 \mathrm{~g}, 0.09 \mathrm{~mol})$, sodium carbonate $(0.7 \mathrm{~g}, 6.6 \mathrm{mmol})$, and $\mathrm{H}_{2} \mathrm{O}$ $(712.2 \mathrm{~g})$. The reaction mixture was degassed by purging with argon for $30 \mathrm{~min}$. A solution of SPS $(0.45 \mathrm{~g}, 1.9 \mathrm{mmol})$ in $\mathrm{H}_{2} \mathrm{O}(10 \mathrm{~g})$ was also degassed. The reaction was started upon the introduction of the initiator solution and was performed at $70^{\circ} \mathrm{C}$ with an impeller speed of $400 \mathrm{rpm}$ for $1 \mathrm{~h}$. The average latex particle size, as determined by dynamic light scattering, was $90 \mathrm{~nm}$. Size exclusion chromatography analysis showed $M_{\mathrm{n}}, M_{\mathrm{w}}$ and PDI values of $495 \mathrm{~kg} / \mathrm{mol}, 944 \mathrm{~kg} / \mathrm{mol}$, and 1.9 , respectively.

\subsection{Preparation of graphene via chemical oxidation/reduction treatment}

In the first approach, graphene, designated ORchem, was synthesized via oxidation of SP-2 graphite using the Hummers method [11] and subsequent sonication of graphene oxide (GO), followed by reduction with hydrazine in the presence of a ten-fold excess of PSS (wt./wt. GO). The entire procedure is described in detail by Stankovich et al. [12]. After the synthesis, the graphene was filtered off with a polyamide membrane filter, which also removes excess of PSS, and dried under vacuum. The product was then re-dispersed in water $(1 \mathrm{mg} / \mathrm{ml}$ ) by a $40 \mathrm{~min}$ sonication treatment (Sonics Vibracell VC750 horn sonicator with a $10 \mathrm{~mm}$ diameter tip) at $20 \mathrm{~W}$ during cooling in an ice-bath to maintain or even to lower the solution temperature.

\subsection{Preparation of graphene via chemical oxidation and thermal reduction treatment}

Graphene (designated ORtherm) was obtained via initial preparation of GO from graphite using the Staudenmaier method [29] followed by a thermo-expansion process. The thermal expansion process consists of a quick exposure of dry GO to a pre-heated tubular furnace at $1025^{\circ} \mathrm{C}$. A detailed description of this process is given by McAllister et al. [14]. Aqueous exfoliated graphene dispersions $(1 \mathrm{mg} / \mathrm{ml})$ were then prepared with the use of SC or PSS surfactants. Both polymers resulted in well-exfoliated and stable dispersions using a 1:1 graphene/surfactant wt.\% ratio. Energy for exfoliation was supplied by sonication following procedure described above (20 W for $40 \mathrm{~min}$ ).

\subsection{Preparation of graphene sonicated in solution}

In the third approach, graphene (designated Sonic) was prepared following the method described by Coleman's group [15,17].
Graphite exfoliation was carried out in SC/water solution using low power ultra-sonication (Bransonic ${ }^{\circledR} 1510 \mathrm{E}, \sim 16 \mathrm{~W}$ ) for long times (up to $400 \mathrm{~h}$ ) followed by centrifugation ( $2000 \mathrm{rpm}$ for $1 \mathrm{~h}$ ).

\subsection{Composites processing}

The compounding procedures for the three different graphene dispersions were identical. Each dispersion was mixed with PS latex, frozen in liquid nitrogen for several minutes, and subsequently freeze dried (Christ Alpha 2-4 freeze dryer operated at $0.2 \mathrm{mbar}$ and $-50^{\circ} \mathrm{C}$ for $24 \mathrm{~h}$ ). The resulting composite powders were heated quickly to $150^{\circ} \mathrm{C}$ and then slowly heated, using small temperature steps, for $20 \mathrm{~min}$ until reach precisely $180^{\circ} \mathrm{C}$, between Teflon sheets, using a Collin Press 300 G. Subsequently the heated material was compression molded into films of 0.5 to $1 \mathrm{~mm}$ thickness at 100 bar for $2 \mathrm{~min}$.

\subsection{Characterization}

UV-vis absorption spectra were recorded with a HewlettPackard 8453 spectrometer operating between 200 and $1100 \mathrm{~nm}$. Small sample volumes of the surfactant/graphene dispersions were taken after the sonication processes and diluted with water by shaking, resulting in a graphene concentration of $0.0125 \mathrm{mg} / \mathrm{ml}$ for all samples. As control experiment the original SC/PSS solutions were diluted and analyzed as above.

A LABRAM confocal Raman spectroscope equipped with an optical microscope was utilized. Samples were irradiated with a red laser $(632.8 \mathrm{~nm})$ supplied by Melles Griot.

Atomic force microscopy (AFM) characterization of graphene was performed with a NT-MDT NTEGRA operated in tapping mode using silicon tips NSG11 (NT-MDT). We deposited our graphene/graphite dispersions onto freshly cleaved mica substrates by spraying a pipette-held droplet $(\sim 10 \mu \mathrm{L})$ with a burst of compressed air. The samples were rinsed with water/alcohol solution for removal of surfactant. The conductive AFM (C-AFM) measurements on composite cross-sections were performed by an NTEGRA Tomo (NT-MDT Co.). The device is a combination of a microtome EM UC6-NT (Leica) and an SPM measuring head. This design allows for alternate microtome cutting and SPM measurements of the sample block-face. The local current measurements were performed in C-AFM mode with a gold-coated silicon cantilever NSC36/Cr-Au (Micromash). The sample was electrically connected to a grounded holder; and a bias of $2 \mathrm{~V}$ was applied [30].

The electrical conductivity was measured using the standard four-point method. The dc electrical resistance of all the samples was measured and compared for the in-plane (longitudinal) direction. Measurements on the transversal direction (through the sample) were not conducted; the anisotropy caused by the compression molding is studied in details somewhere else [31]. Parallel contact lines, with $1 \mathrm{~cm}$ in length and with a $1 \mathrm{~cm}$ interval, were drawn on the composite film with conductive-silver paint (Fluka). All conductivity measurements were performed at room temperature with a Keithley 6512 programmable electrometer. For each sample, conductivity data represent the average over 10 consecutive measurements in a voltage range from 0 to $10 \mathrm{~V}$ and at frequencies between 50 and $60 \mathrm{~Hz}$.

\section{Results and discussion}

\subsection{Graphene platelets: dispersion and morphological analyses}

Raman spectra (Fig. 1a) were first investigated in order to determine the "quality" of the exfoliated graphene. It is well known that Raman spectroscopy is suitable not only for determination of the number of layers, but also for detecting the presence of structural 

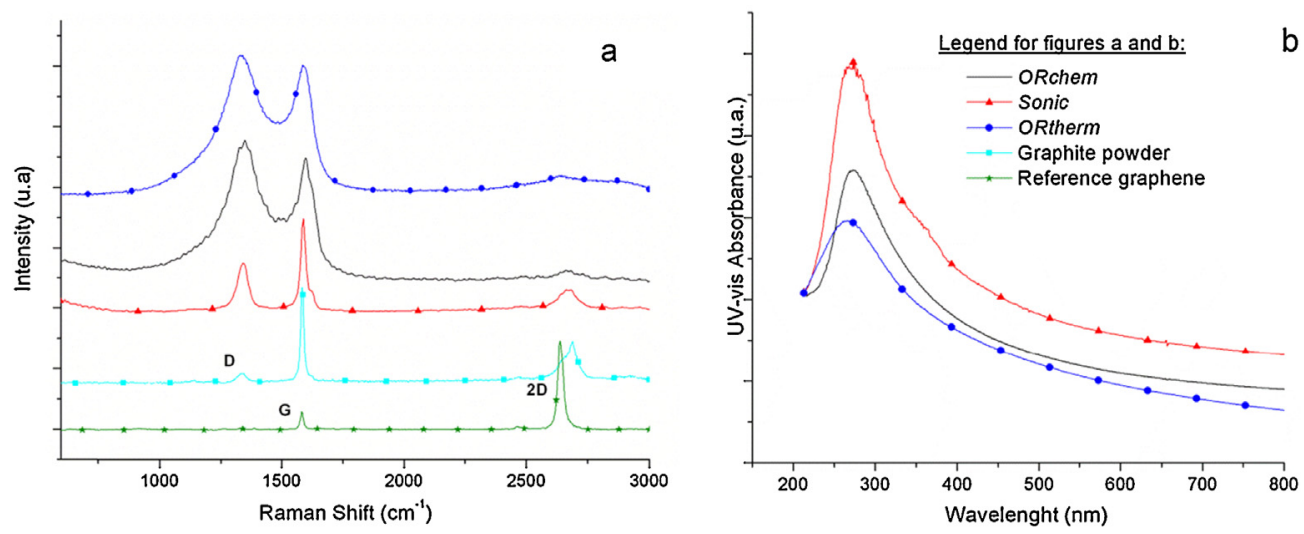

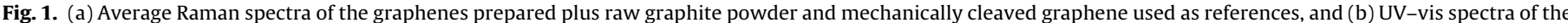
three dispersions used for composite manufacturing. No dispersion was prepared using Graphite powder and Reference mechanically cleaved graphene.

defects [32-34]. Thin films were produced from all three graphene dispersions by drop casting [35]. For each film we measured Raman spectra at multiple locations. The spectra for the untreated graphite powder and the micro-mechanically cleaved graphene reference are shown for comparison.

For ORchem and ORtherm graphene, the prominent D peak (absent in mechanically cleaved graphene and small in graphite powder references) is attributed to the presence of $s p^{3}$ carbon vibrations in the basal carbon plane. Several forms of defects, which could include residual carboxylic acids, epoxides, or ketones, may well cause lattice distortions, accounting for the increased D band intensity. The intensity of the 2D peak of the ORchem and ORtherm samples with respect to the D and G peaks is very small, most likely due to the discussed structural disorder. On account of the low intensity and broadness, we only report here a small shift for the $2 \mathrm{D}$ peaks to lower wavenumbers as compared to the untreated graphite sample. The absence of any prominent shoulder on the 2D peak indicates that only graphene having a few layers are present in solution $[32,36]$.

The introduction of edge defects in graphene dispersions submitted only to long-term sonication (Sonic) is unavoidable, as large crystallites are cut into smaller platelets during processing. However, the D band observed for Sonic platelets (see Fig. 1a) is both narrower and less intense as in ORchem and ORtherm samples, strongly suggesting that the former graphene contains less defects [15]. Overall for sonic platelets, the 2D band displays a nongraphite-like character. The spectra were consistent with platelets having a few graphene layers. As mentioned before for ORchem and ORtherm samples, the also non-homogeneous and low 2D band intensity of sonic platelets prevents a more detailed conclusion.

By UV-vis analysis the highest absorbance, i.e. the best dispersion, was measured for the Sonic samples, followed by the ORchem samples (Fig. 1b). The selection of surfactants for each dispersion method was based on the best performing combinations (surfactant + method) as learned from previous reports [17,21]. We would like to stress that a good dispersion with high absorbance measured by UV-vis does not necessarily mean that it has a large number of single layer graphene platelets. It should be more seen as an indication that a large amount of small particles are present, which remain suspended and absorb radiation [37,38]. Although all sample dispersions were visually stable, black colored and without any signs of settling in the short term ( 1 week), the only dispersion without any trace of settling in the long-term ( 6 months) was the Sonic sample.

AFM was extensively applied to determine the sheet thickness, morphological features and lateral dimensions of the graphene samples. Right after chemical oxidation, the first step for preparation of ORchem and ORtherm graphene, the formation of a great majority of $1 \mathrm{~nm}$ thick GO platelets was confirmed [12,22]. The oxidation process yielded almost $100 \%$ of GO with a thickness of around $1 \mathrm{~nm}$ and surface areas between 1 and $3 \mu \mathrm{m}^{2}$. Images are not shown.

AFM analyses of the chemically treated graphene after reduction are shown in Fig. 2. A wrinkling of the platelets is visible (see Fig. 2a and d, and black arrows in Fig. 2c and f). This wrinkling is clearly more severe for the ORtherm graphene, probably because of the fast "explosion" that the GO is submitted to during reduction. It was also observed that sheet agglomeration and a decreasing sheet surface area may be a result of the chemical reduction process. The decreasing sheet size is just indicative as the folding/agglomeration of graphene prevents to obtain reliable statistical data. Measurements of the sheet thickness on flat areas indicated mostly monolayers or a few layers of graphene stacked together. Thicknesses were between 1 and $3 \mathrm{~nm}$ for more than $90 \%$ of the ORchem sheets and for more than $75 \%$ of the ORtherm sheets (see Fig. 2b and e). The roughness of exfoliated graphene is higher than the mechanically cleaved graphene reference prepared via the scotch tape method [3], probably due to defects, un-removed functional groups, or surfactants on treated surfaces.

AFM analysis of non-oxidized (Sonic) graphene submitted only to long-term mechanical sonication shows, on average, thicker and smaller platelets. In contrast to previous studies [15,17], a great majority (>90\%) of small multi-layer graphene particles are present, exhibiting a thickness between 5 and $25 \mathrm{~nm}$ (see Fig. $2 \mathrm{~h}$ ). Some traces of more than $100 \mathrm{~nm}$ thick graphite platelets were also found, but discarded from further analysis. Obviously, for more than $5 \mathrm{~nm}$ thick platelets, no wrinkling was observed. The average surface areas were below $1 \mu \mathrm{m}^{2}$. In summary, the Sonic approach provides smaller multi-layer graphene platelets as compared to the two oxidation/reduction methods. Nevertheless, Sonic dispersions show a much better long term-stability after centrifugation, without visible settling of particles.

Table 1 summarizes the main results obtained from the Raman spectroscopy, UV-vis absorbance analysis, and AFM morphological characterization of the graphene samples.

\subsection{PS/graphene composite analyses}

The three different graphene dispersions were mixed with polystyrene (PS) latex and manually stirred, followed by freezedrying and compression molding, resulting in composite tablets with thicknesses ranging from 0.5 to $1.0 \mathrm{~mm}$. The composite processing was identical for all dispersions. Finally, the electrical conductivity of the composites was measured as a function of the 

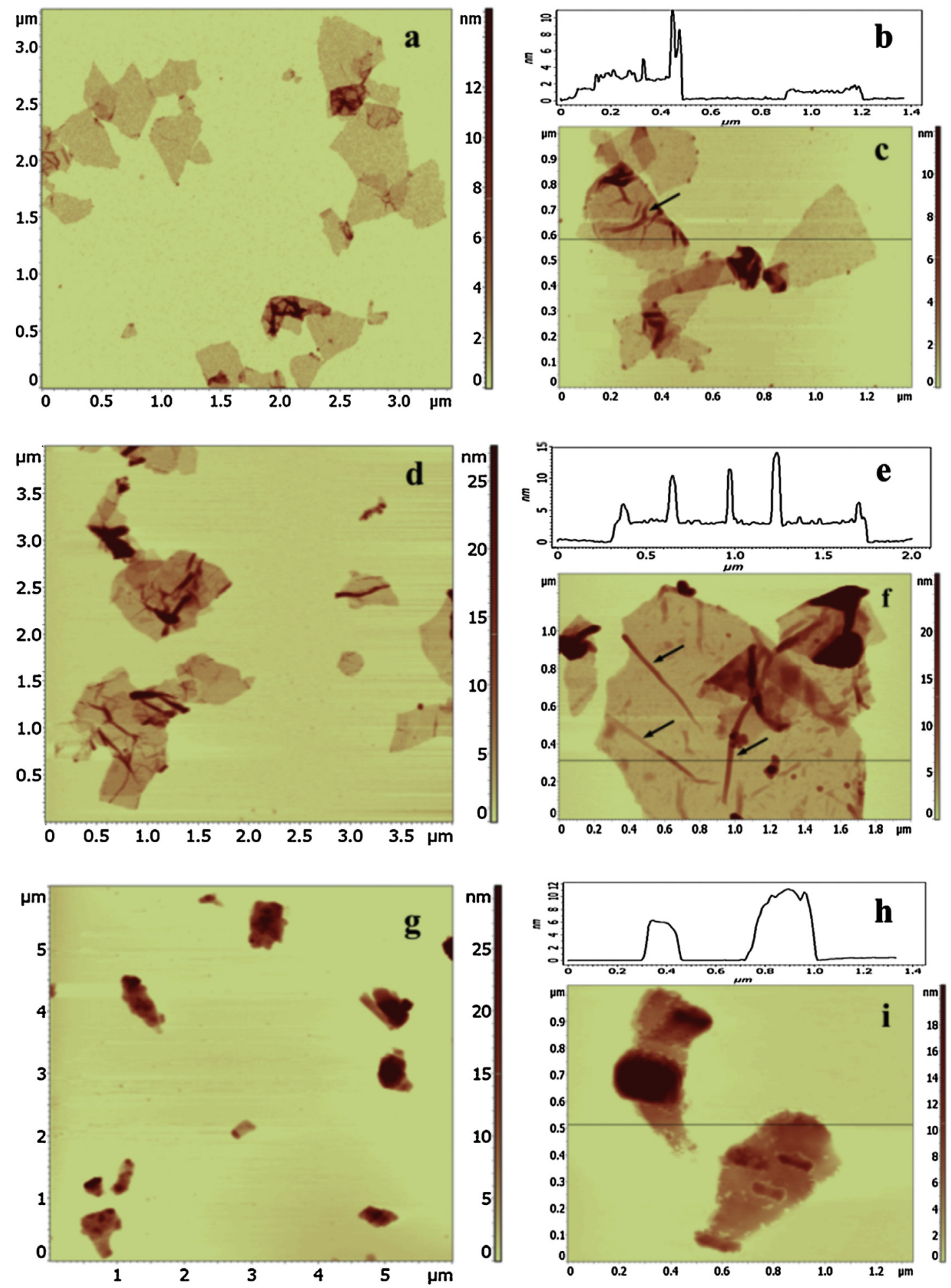

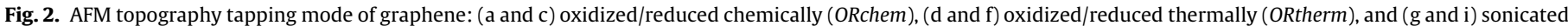

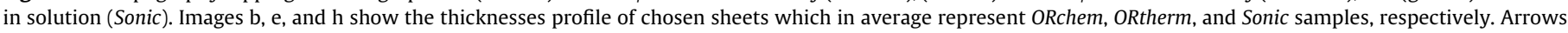
indicate wrinkling/folding of the sheets.

Table 1

Summary of dispersion and morphological analyses of the fillers.

\begin{tabular}{|c|c|c|c|c|c|}
\hline Graphene sample & Dispersion (UV-vis) & Amount of defects (Raman) & Lateral dimension $\left(\mu \mathrm{m}^{2}\right)$ & Platelet thickness (nm) & Wrinkling/folding \\
\hline ORchem & Good & High & $1-3$ & $1-3(>90 \%)$ & Average \\
\hline ORtherm & Average & High & $1-3$ & $1-3(>75 \%)$ & High \\
\hline Sonic & Excellent & Low & $<1$ & $5-25(>90 \%)$ & Low \\
\hline
\end{tabular}




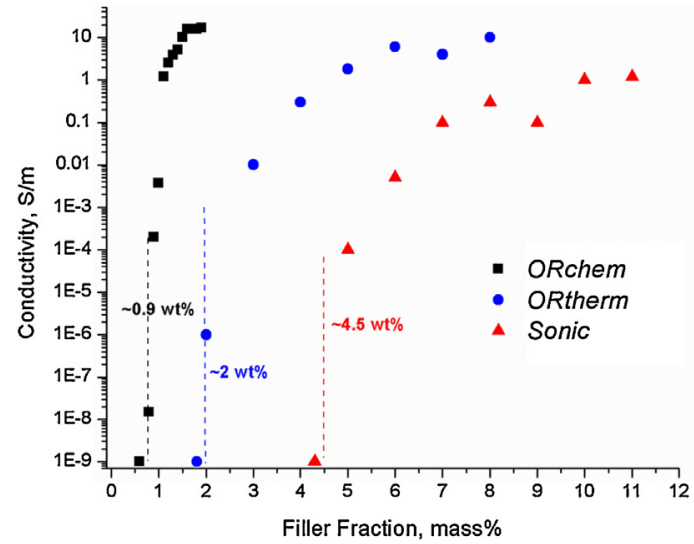

Fig. 3. Electrical conductivity of graphene/PS composites as a function of graphene weight fraction. Values represent an average of 10 measurements for each sample; standard deviations are below $10 \%$.

nanofiller content (Fig. 3). The composites exhibit a conductivity percolation threshold when the filler content is increased to form a continuous conductive path. The percolation threshold depends critically on the dispersion state, the nature of the contacts which defines the electron transport mechanism, and filler content, type, and dimensions.

For the ORchem samples, at a concentration of $\sim 0.9 \mathrm{wt} . \%$ the conductivity increases dramatically and reaches $15 \mathrm{~S} / \mathrm{m}$ at 1.5 to $2 \mathrm{wt} . \%$. This value is, to the best of our knowledge, the highest value measured for graphene/PS composites with graphene loadings below $10 \mathrm{wt}$.\%. For the remaining two approaches, percolation occurs at loadings of $\sim 2 \mathrm{wt} . \%$ for the ORtherm and $\sim 4.5 \mathrm{wt} . \%$ for the Sonic composites, respectively. Here, the maximum conductivities measured were $10 \mathrm{~S} / \mathrm{m}$ for ORtherm and $1 \mathrm{~S} / \mathrm{m}$ for Sonic. ORtherm graphene/PS composites, prepared from the same optimized dispersions and stabilized with PSS or SC surfactants, show similar degrees of exfoliation, exhibit almost identical percolation threshold curves ( $\sim \mathrm{wt} . \%)$ and show the same final conductivity values $(\sim 10 \mathrm{~S} / \mathrm{m})$. Therefore, the choice of SC or PSS does not significantly influence the final conductivity and percolation in the final composites. However, we cannot deny the importance of the choice of the surfactant for a proper initial exfoliation in water.

Based on Raman and UV-vis alone, one would expect the lowest percolation threshold for the Sonic composites, as they presented the least structural damage during exfoliation and the most stable suspensions (highest UV-vis absorption and long-term stability). This was not observed in the actual conductivity measurements; therefore, conductivity is not only determined by defect density in the exfoliated graphite or the stability of the dispersion. Besides the fact that aqueous graphene dispersions with relatively low stability and relatively low degrees of exfoliation might exhibit lower percolation thresholds when compared to PS composites based on more stable dispersions with higher degrees of graphene exfoliation [31], we speculate that the percolation threshold is, in our case, mainly related to the different dimensions of the nanofillers. Long term sonication of graphite leads to a reduced lateral size of the platelets as compared to the other techniques, and mainly leads to thicker samples. These features might have a crucial influence on the higher percolation threshold obtained for these samples as compared to the ones obtained for ORchem and ORtherm samples.

A nano-scale view of the conductive network is provided by conductive atomic force microscopy. The C-AFM tip measures the current throughout the volume of the composites specimen at a given voltage, which is transported via the graphene network to the ground contact. That means that only platelets that are grounded are monitored. Observed differences in current are determined by the path length and the intra-network graphene junctions, which may have a different resistivity [30]. Graphene sheets forming sub-networks without ground connection show no current. In this way, C-AFM provides a current distribution image from which the conductive network can be distinguished from the insulating polymer/filler matrix. In Fig. 4, the red/green brighter colored areas (which correspond to graphene in a cross-section topographic image) show non-zero current levels, indicating the presence of conductive pathways. The ORchem composites show a high number of conductive paths at 2 wt.\% filler contents.

In addition, a current vs. voltage $(I-V)$ curve was measured at different points from at least 5 graphene clusters. When analyzing the various $I-V$ curves, corresponding to each of the different composites, we observed differences in the curve shapes. Most notably, we observed for the first time that $I-V$ curves obtained from ORchem composites show a linear $I-V$ relation (inset in Fig. 4a) for most graphene clusters, indicating predominantly Ohmic contacts between graphene sheets [39]. For the other two samples we observe the conventional exponential-like $I-V$ curve relation. This latter behavior is associated to tunneling electron transport [40,41], due to non-perfect contacts and the presence of surfactant or polymers in between the graphene sheets. AFM and SEM analyses show that ORchem graphene platelets are larger, thinner and less wrinkled than the other two graphene types. This would allow a larger direct contact area between the platelets, considering that the same filler weight concentration is present. A more detailed investigation on this topic is ongoing in our group.

Fig. 5 shows charge contrast SEM images of composite crosssections as presented in Fig. 4. Besides a more or less dark background, referring to the non-conductive matrix, bright areas are visible, which represent the graphene sheets. Because of the
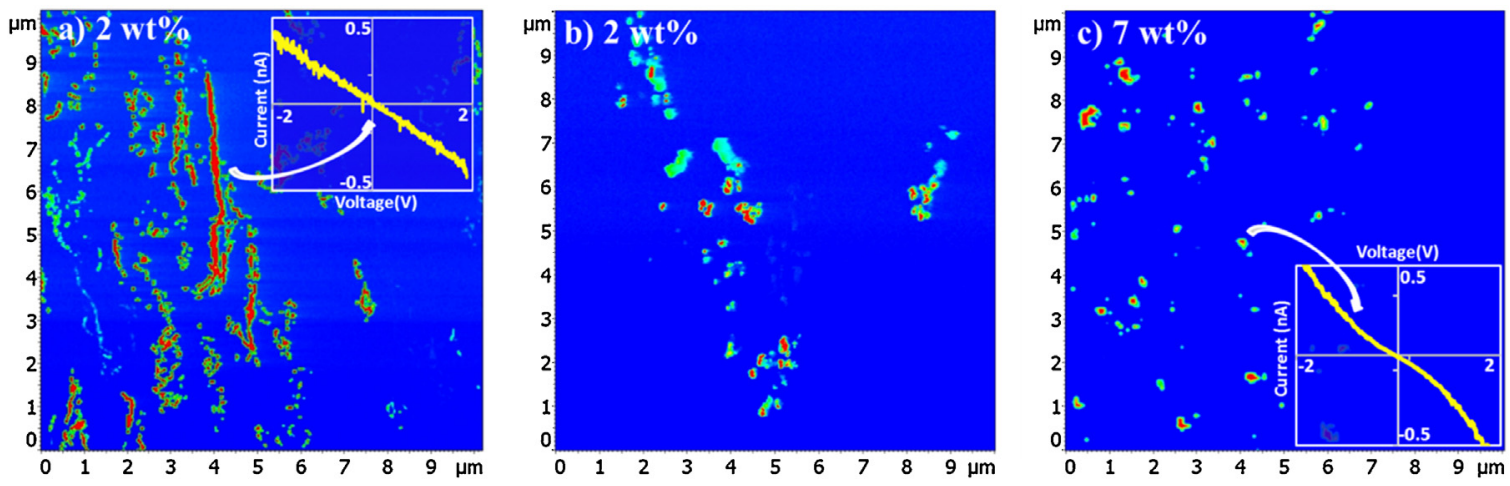

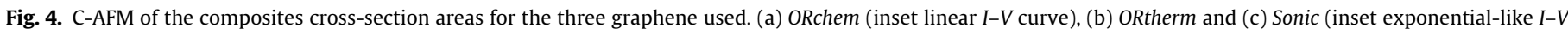
curve) composites. Green/red spots correspond to graphene paths which contribute to conductivity through the sample. 

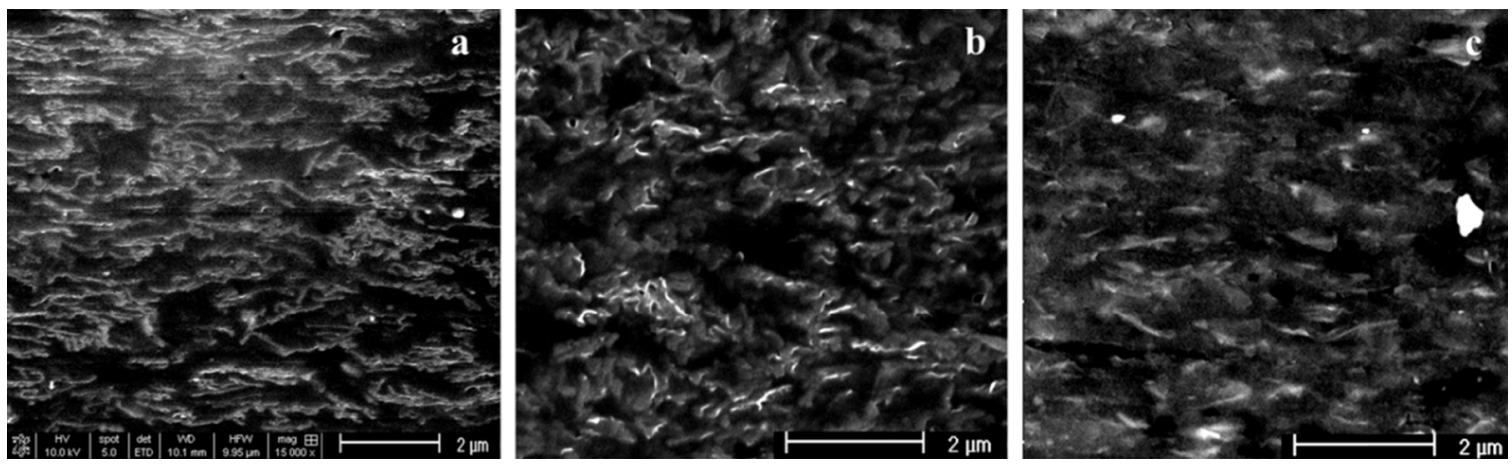

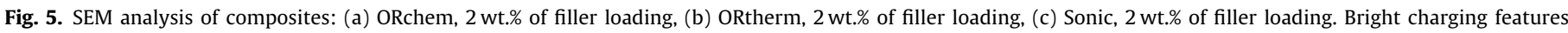
correspond to the conductive graphene fillers inside the isolating PS polymer.

Table 2

Summary of the electrical conductive behavior and morphological analyses of the graphene/PS composites.

\begin{tabular}{|c|c|c|c|c|c|}
\hline Composite sample & $\begin{array}{l}\text { Max. electrical } \\
\text { conductivity }(\mathrm{S} / \mathrm{m})\end{array}$ & $\begin{array}{l}\text { Percolation threshold } \\
\text { (filler wt.\%) }\end{array}$ & $\begin{array}{l}\text { Electronic transport } \\
\text { (C-AFM) }\end{array}$ & $\begin{array}{l}\text { Filler dispersion } \\
(\mathrm{SEM})\end{array}$ & $\begin{array}{l}\text { Filler morphology } \\
(\mathrm{SEM})\end{array}$ \\
\hline ORchem & $15^{\mathrm{a}}$ & $0.9^{\mathrm{a}}$ & Ohmic & Good & Elongated \\
\hline ORtherm & $10^{\mathrm{a}}$ & $2^{\mathrm{a}}$ & Tunneling & Good & Elongated \\
\hline Sonic & $1^{\mathrm{a}}$ & $4.5^{\mathrm{a}}$ & Tunneling & Good & Bulk pieces \\
\hline
\end{tabular}

a Standard deviations are below $10 \%$.

differences in charge transport between graphene and the polymer matrix, the secondary electron emission is higher at the graphene location. This results in the contrast between the graphene network (bright) and the polymer matrix (dark) [42]. Therefore, by using charge contrast imaging at high acceleration voltage we are able to gain representative information on the organization of a conductive network of graphene sheets in a polymer matrix. We could again notice the presence of more elongated filler arrangements for the ORchem material. It is also possible to identify the wrinkled and agglomerated graphene structures (the not so bright features in the background of Fig. 5b) for the ORtherm composites. For the Sonic composites we can only observe non-defined bulk pieces of filler material along the cross-section area instead of platelets. The bright white dot that can be seen in Fig. 5c most probably is a piece of graphite inside the composite. Overall, in all samples the graphene filler was homogeneously distributed within the matrix.

Table 2 summarizes the main results obtained from the composite characterization, which includes the four-point conductivity measurements, C-AFM and high-charge contrast SEM morphological analyses.

\section{Conclusions}

Graphene, produced via difference water-based methods, was successfully used for the manufacturing of conductive graphene/PS composites, using latex technology. With respect to graphene production, Raman analyses confirmed that oxidation/reduction methods introduce structural distortions/defects to the basal plane of graphene. Less damage was noticed for graphite which was submitted only to long-term sonication. Dispersions produced with graphene using this latter approach showed also higher long-term stability. AFM showed that the GO reduction techniques used in this work yield thin graphene platelets and, as a consequence, also induce wrinkling/agglomeration and possible size reduction of the platelets, especially for the ORtherm samples. Nevertheless, the thickness of the majority of the sheets was between 1 and $3 \mathrm{~nm}$, corresponding to a single or only a few layers of graphene. The Sonic graphene was thicker, indicating multi-layer graphene $(5-25 \mathrm{~nm})$ and the average size was smaller. As these samples are much thicker, no wrinkling was observed.
The conductivities of the ORchem composites (by both four point and local current measurements) reveal high values up to $15 \mathrm{~S} / \mathrm{m}$ and a low percolation threshold (0.9 wt.\%). By the use of latex technology, well-dispersed graphene sheets in PS matrix were obtained and visualized using charge contrast SEM. SEM and C-AFM illustrate the different graphene shapes, even inside the polymer, depending on the filler production method. Interestingly, differences in electronic transport behavior were observed, which suggest mostly direct contact transport for ORchem graphene in contrast to tunneling for mostly of the ORtherm and Sonic graphene conductive paths. ORtherm composites produced with both PSS and SC surfactant exhibited almost identical percolation thresholds and final conductivities, indicating negligible influence of the surfactant, at the final stage, on these properties. However, surfactants have an important role during initial dispersion in water. Utilizing our dispersions, optimized with ionic surfactants and ultra-sonication, and same composite processing conditions, we confirm that the conductive properties of the final composites mainly depend on the initial morphological characteristics of the produced graphene and its self-organization inside the polymer matrix [43,44]. Notably, we verified that these characteristics have an important influence on the type of electronic transport behavior through the composite.

\section{Acknowledgements}

This work is part of the Research Program of the Dutch Polymer Institute (DPI), project nr. \#648. Marco Hendrix and Nick Lousberg are acknowledged for their support with the AFM and SEM analyses and Heiner Friedrich for suggestions and corrections.

\section{References}

[1] J.R. Potts, et al., Graphene-based polymer nanocomposites, Polymer 52 (1) (2010) 5-25.

[2] H. Kim, A.A. Abdala, C.W. Macosko, Graphene/polymer nanocomposites, Macromolecules 43 (16) (2010) 6515-6530.

[3] K.S. Novoselov, et al., Electric field effect in atomically thin carbon films, Science 306 (5696) (2004) 666-669.

[4] C. Berger, et al., Ultrathin epitaxial graphite: 2D electron gas properties and a route toward graphene-based nanoelectronics, J. Phys. Chem. B 108 (52) (2004) 19912-19916

[5] W.A. de Heer, et al., Epitaxial graphene, Solid State Commun. 143 (1-2) (2007) 92-100. 
[6] K.S. Kim, et al., Large-scale pattern growth of graphene films for stretchable transparent electrodes, Nature 457 (7230) (2009) 706-710.

[7] X.S. Li, et al., Large-area synthesis of high-quality and uniform graphene films on copper foils, Science 324 (5932) (2009) 1312-1314.

[8] A. Reina, et al., Large area few-layer graphene films on arbitrary substrates by chemical vapor deposition, Nano Lett. 9 (1) (2009) 30-35.

[9] G. Eda, G. Fanchini, M. Chhowalla, Large-area ultrathin films of reduced graphene oxide as a transparent and flexible electronic material, Nat. Nanotechnol. 3 (5) (2008) 270-274.

[10] C. Berger, et al., Electronic confinement and coherence in patterned epitaxial graphene, Science 312 (5777) (2006) 1191-1196.

[11] W.S. Hummers, R.E. Offeman, Preparation of graphitic oxide, J. Am. Chem. Soc. 80 (6) (1958) 1339.

[12] S. Stankovich, et al., Synthesis of graphene-based nanosheets via chemical reduction of exfoliated graphite oxide, Carbon 45 (7) (2007) 1558-1565.

[13] D. Li, et al., Processable aqueous dispersions of graphene nanosheets, Nat. Nanotechnol. 3 (2) (2008) 101-105.

[14] M.J. McAllister, et al., Single sheet functionalized graphene by oxidation and thermal expansion of graphite, Chem. Mater. 19 (18) (2007) 4396-4404.

[15] M. Lotya, et al., Liquid phase production of graphene by exfoliation of graphite in surfactant/water solutions, J. Am. Chem. Soc. 131 (10) (2009) 3611-3620.

[16] Y. Hernandez, et al., High-yield production of graphene by liquid-phase exfoliation of graphite, Nat. Nanotechnol. 3 (9) (2008) 563-568.

[17] M. Lotya, et al., High-concentration surfactant-stabilized graphene dispersions, ACS Nano 4 (6) (2010) 3155-3162.

[18] H. Bai, C. Li, G.Q. Shi, Functional composite materials based on chemically converted graphene, Adv. Mater. 23 (9) (2011) 1089-1115.

[19] H. Chen, et al., Mechanically strong, electrically conductive, and biocompatible graphene paper, Adv. Mater. 20 (18) (2008) 3557.

[20] S. De, et al., Flexible, transparent, conducting films of randomly stacked graphene from surfactant-stabilized. Oxide-free graphene dispersions, Small 6 (3) (2008) 458-464.

[21] S. Stankovich, et al., Graphene-based composite materials, Nature 442 (7100) (2006) 282-286.

[22] E. Tkalya, et al., Latex-based concept for the preparation of graphene-based polymer nanocomposites, J. Mater. Chem. 20 (15) (2010) 3035-3039.

[23] M. Ghislandi, et al., High performance graphene- and MWCNTs-based PS/PPO composites obtained via organic solvent dispersion, Compos. Sci. Technol. 80 (0) (2013) 16-22.

[24] M. Ghislandi, et al., Electrical conductivities of carbon powder nanofillers and their latex-based polymer composites, Compos. A: Appl. Sci. Manuf. 53 (0) (2013) 145-151.

[25] M. Ghislandi, Nano-scaled Carbon Fillers and their Functional Polymer Composites, Eindhoven University of Technology, Eindhoven, 2012.

[26] O. Regev, et al., Preparation of conductive nanotube-polymer composites using latex technology, Adv. Mater. 16 (3) (2004) 248.
[27] N. Grossiord, J. Loos, C.E. Koning, Strategies for dispersing carbon nanotubes in highly viscous polymers, J. Mater. Chem. 15 (24) (2005) 2349-2352.

[28] J.R. Yu, et al., Characterization of conductive multiwall carbon nanotube/polystyrene composites prepared by latex technology, Carbon 45 (15) (2007) 2897-2903.

[29] L. Staudenmaier, Verfahren zur Darstellung der Graphitsäure, Berichte der deutschen chemischen Gesellschaft 31 (2) (1898) 1481-1487.

[30] A. Alekseev, et al., Conductive network inside graphene/polymer composites, Adv. Funct. Mater. (2011), http://dx.doi.org/10.1002/adfm.20110179.

[31] B. Marinho, et al., Electrical conductivity of compacts of graphene, multi-wal carbon nanotubes, carbon black, and graphite powder, Powder Technol. 221 (2012) 351-358

[32] A.C. Ferrari, et al., Raman spectrum of graphene and graphene layers, Phys. Rev. Lett. 97 (18) (2006) p4.

[33] A.C. Ferrari, Raman spectroscopy of graphene and graphite: disorder, electron-phonon coupling, doping and nonadiabatic effects, Solid State Commun. 143 (1-2) (2007) 47-57.

[34] M. Ghislandi, et al., Tip-enhanced Raman spectroscopy and mapping of graphene sheets, Appl. Spectrosc. Rev. (2012).

[35] W. Du, et al., A simple and practical route to prepare useable pristine graphene for electrochemical applications, Chem. Eng. J. 262 (2015) 658-664.

[36] D. Yang, et al., Chemical analysis of graphene oxide films after heat and chemical treatments by X-ray photoelectron and Micro-Raman spectroscopy, Carbon 47 (1) (2009) 145-152.

[37] J. Yu, et al., Controlling the dispersion of multi-wall carbon nanotubes in aqueous surfactant solution, Carbon 45 (3) (2007) 618-623.

[38] N. Grossiord, et al., Conductive carbon-nanotube/polymer composites: spectroscopic monitoring of the exfoliation process in water, Compos. Sci. Technol. 67 (5) (2007) 778-782.

[39] A. Trionfi, et al., Direct imaging of current paths in multiwalled carbon nanofiber polymer nanocomposites using conducting-tip atomic force microscopy, J. Appl. Phys. 104 (8) (2008) p6.

[40] C. Gau, C.Y. Kuo, H.S. Ko, Electron tunneling in carbon nanotube composites, Nanotechnology 20 (39) (2009) p6.

[41] A. Celzard, et al., Non-linear current-voltage characteristics in anisotropic epoxy resin-graphite flake composites, J. Mater. Sci. 32 (7) (1997) 1849-1853.

[42] J. Loos, et al., Visualization of single-wall carbon nanotube (SWNT) networks in conductive polystyrene nanocomposites by charge contrast imaging, Ultramicroscopy 104 (2) (2005) 160-167.

[43] E. Tkalya, et al., Experimental and theoretical study of the influence of the state of dispersion of graphene on the percolation threshold of conductive graphene/polystyrene nanocomposites, ACS Appl. Mater. Interfaces 6 (17) (2014) 15113-15121.

[44] A. Celzard, et al., Critical concentration in percolating systems containing a high-aspect-ratio filler, Phys. Rev. B 53 (10) (1996) 6209-6214. 